\title{
Effect of Personality, Power, and Emotion on Developing the 2017-2022 Philippine Health Research Agenda: A Case Study
}

\author{
Alejandra M. Libunao, ${ }^{1}$ Reneepearl Kim P. Sales, ${ }^{2}$ Jaifred Christian F. Lopez, ${ }^{2}$ Ma. Rowena H. Alcido, ${ }^{2,3}$ \\ Lester Sam A. Geroy, ${ }^{2}$ Joseph V. Oraño ${ }^{2}$ and Rafael Deo F. Estanislao ${ }^{2}$ \\ ${ }^{1}$ HealthDev Institute, Inc., Loyola Heights, Quezon City, Philippines \\ ${ }^{2}$ Alliance for Improving Health Outcomes, Inc., West Avenue, Quezon City, Philippines \\ ${ }^{3}$ Development Academy of the Philippines, Pasig City, Philippines Manila
}

\begin{abstract}
Background. Social dynamics, specifically personalities, power dynamics, and emotions, have been shown to influence the methods, outputs, and quality of multi-stakeholder processes, especially the development of a national health research agenda.

Objective and Methods. Using a case analysis approach utilizing related conceptual frameworks, the paper determined how personalities, power dynamics, and emotions affected the research priority-setting exercise, identified lessons learned, and recommended how to effectively manage these social dynamics in consultations. Data gathering methods were participant observation and process documentation, results of which were codified and analyzed.

Results. Dominant personalities, stakeholders with power, and stakeholders that openly expressed dissatisfaction were most likely to attempt to change the methods and final outputs of the consultation, with varying level of success. Other dominant personalities used their power constructively for a smooth flow of generating and agreeing on ideas.

Conclusion. In this case, social dynamics was shown to heavily influence the decision-making process, thus underlining its importance in organizing multisectoral representation. Effectively managing social dynamics may thus have to consider building trust and respect between participants, mediating discussions, reaching a mutually beneficial solution, and establishing and implementing mutually agreed house rules. The significant role of facilitators in developing a climate for truly inclusive participation must also be recognized.
\end{abstract}

Key Words: power, expressed emotions, consensus, personality

\section{INTRODUCTION}

Corresponding author: Reneepearl Kim P. Sales, RMT, MLS(ASCPi)CM, MSc

Alliance for Improving Health Outcomes 62 West Avenue, Quezon City 1104, Philippines Email: kimsales@aiho.org.ph
Research priority setting is a process that generates and prioritizes research themes that, when targeted by researchers and policymakers, has the greatest potential to benefit the general public. ${ }^{1}$ This requires a transparent process that engages stakeholders in order to channel resources efficiently into areas relevant to them. ${ }^{2}$ Various methods of prioritysetting are employed and there is an increasing recognition of the role that inclusiveness plays in shaping research priority setting methods. ${ }^{3}$ Thus, in conducting a research priority setting exercise, appropriate representation of all stakeholders that takes into account their expertise, gender, geographical location, and other factors is important. ${ }^{1}$ It is likewise crucial that stakeholders are engaged effectively and 
fairly to maximize their involvement in the research priority setting process, ${ }^{1,4}$ especially since, in a consensus-building approach, stakeholders usually come from diverse social and cultural backgrounds. The behavior of groups based on interactions between individuals, or their social dynamics, may thus affect the conduct and results of the exercise. ${ }^{4,5} \mathrm{An}$ imbalance in social dynamics has been reported to result in perceived unfairness, reduced motivation, and doubts over the legitimacy of the priority setting process and results. ${ }^{3}$

Three factors of social dynamics were considered in this paper: 1) personality, 2) power and 3) emotion. ${ }^{6}$ The American Psychological Association defines personality as "individual differences in characteristic patterns of thinking, feeling, and behaving." In a group decision-making process, personality has been recognized as one of the underlying attributes of diversity and evidence shows that a more diverse group of stakeholders in many attributes, including personality, improves decision-making processes and outcomes. ${ }^{8-13}$ Power is the ability to influence others and is usually associated with resources, participation in decision-making processes, and terms of engagement. ${ }^{14}$ The difference in the amount of power between stakeholders in a group leads to power dynamics, with some better able to assert their viewpoints as others look for other ways to do so. Finally, emotion, as defined by Nerines, is " a complex psychological event that involves a mixture of reactions: (1) a physiological response (usually arousal), (2) an expressive reaction (distinctive facial expression, body posture, or vocalization), and (3) some kind of subjective experience (internal thoughts and feelings). "15 Recent behavioral and neuroscience research shows that emotions are a necessary input in the decision-making process and that rationality of decisions decrease as emotions become more absent in the decision-making process. ${ }^{16}$ A report published in 2016 ranked the Philippines as the most emotional country in the world, tied with Ecuador, El Salvador, and Guatemala. ${ }^{17}$ In addition, a study that classified emotions of Filipinos through word banks for one month revealed that the top three emotions expressed by Filipinos were neutral (73\%), happy (18\%), and sad (3\%). ${ }^{18}$

\section{THE CASE: NATIONAL HEALTH RESEARCH AGENDA 2017-2022 DEVELOPMENT}

The Philippine National Health Research System, with its goal to enhance health status through health research, generates the National Unified Health Research Agenda (NUHRA) as one of its core areas. The development of the NUHRA 2017-2022 was guided by the Kingdon Multiple Streams model. This model asserts that alignment of three streams can create a "policy window" which leads to greater acceptability and adoption of a policy by stakeholders. ${ }^{19}$ Stakeholders were involved in each stream during the development of the NUHRA 2017-2022. Regional health research development consortiums and region-based coordinators were involved in the process of determining national mood, national \& regional contexts, and issues, needs, and gaps at the regional level. The verification of these information and research priority exercise through consensus-building was done by the conduct of regional consultations. Seventeen regional consultations were conducted between March and June 2017. There were 312 participants in these consultations: $44 \%$ from government institutions, 34\% from academic institutions, $11 \%$ from nongovernment organizations (NGO), 9\% from health facility, and $2 \%$ from other types of institutions.

Existing literature on research priority setting have focused mostly on the results of the research priority setting exercise, the representation of stakeholders, and the impact on health systems and research output. Only a few studies have explored how social dynamics affect the consensusbuilding process and its outcomes. Cognizant of the need to ensure smooth flow of discussion to produce reliable research agenda, we investigated the impact of three social dynamic factors on the standard methodology and results of the regional health research priority setting. Moreover, this study identified lessons and recommendations on how to effectively manage consultations.

\section{METHODS}

\section{Data Collection}

This study used a qualitative, observational, scoping approach. First-hand data were collected from 17 regional workshops through a structured observation and analysis of audio-tapes, which allowed for validation of content of messages and manifestations of emotion. The following questions were used to guide the observation of participants:

- Who raised the questions?

- Who responded?

- Were there agreements or disagreements?

Accompanying these guide questions for participant observation were instructions to monitor for remarkable body language, and tone and volume of voice. Observations were then categorized, counted and summarized; while similarities were also identified.

\section{Data Analysis}

Three different frameworks or models were used to analyze personality, power, and emotion. The Five Factor Model (Table 1) was used to identify personalities. This model classifies personalities into five: openness, conscientiousness, extraversion, agreeableness, neuroticism..$^{20}$

Power dynamics were identified through the faces of power framework which classifies power as visible, hidden, and invisible (Table 2). The framework provides guide questions on how to categorize power dynamics in a setting that shapes national arena, such as a health research priority setting exercise. ${ }^{21}$ 
Table 1. Description of each Five Factor Model personality

\begin{tabular}{ll}
\hline Openness & $\begin{array}{l}\text { Tendency to be informed, creative, insightful, } \\
\text { curious and having a variety of experience }\end{array}$ \\
\hline Conscientiousness & $\begin{array}{l}\text { Tendency to show self-discipline, act dutifully, } \\
\text { and aim for achievement. It means planned } \\
\text { rather than spontaneous behavior }\end{array}$ \\
\hline Extraversion & $\begin{array}{l}\text { To have energy, positive emotions, and the } \\
\text { tendency to be sociable }\end{array}$ \\
\hline Agreeableness & $\begin{array}{l}\text { Tendency to be compassionate, trusting } \\
\text { and cooperative rather than suspicious and } \\
\text { antagonistic towards others }\end{array}$ \\
\hline Neuroticism & $\begin{array}{l}\text { Tendency to experience unpleasant emotions } \\
\text { easily, such as anger, anxiety, depression, } \\
\text { or vulnerability }\end{array}$ \\
\hline
\end{tabular}

Table 2. Faces of power and their definitions

\begin{tabular}{ll}
$\begin{array}{l}\text { Visible: observable } \\
\text { decision-making }\end{array}$ & $\begin{array}{l}\text { Visible and definable aspects of political power: } \\
\text { rules, structure, authorities, institutions, and } \\
\text { procedures. Includes laws, mandates, budgets. }\end{array}$ \\
\hline $\begin{array}{l}\text { Hidden: setting the } \\
\text { political agenda }\end{array}$ & $\begin{array}{l}\text { Certain powerful people and institutions } \\
\text { maintain their influence by controlling who } \\
\text { gets to the decision-making table and what } \\
\text { gets on the agenda. These dynamics exclude } \\
\text { and devalue the concerns and representation } \\
\text { of other less powerful groups. By preventing } \\
\text { important voices and issues from getting a fair } \\
\text { public hearing, policymaking can be skewed to } \\
\text { benefit a few at the expense of the majority. }\end{array}$ \\
\hline Invisible: shaping & $\begin{array}{l}\text { Shapes the psychological and ideological } \\
\text { meaning }\end{array}$ \\
& $\begin{array}{l}\text { boundaries of participation. Problems and } \\
\text { making table but also from minds of } \\
\text { stakeholders involved }\end{array}$ \\
\hline
\end{tabular}

Table 3. Parrot's Emotion Classification

\begin{tabular}{|c|c|c|}
\hline Primary emotion & Secondary emotion & Tertiary emotions \\
\hline \multirow[t]{3}{*}{ Love } & Affection & Adoration, fondness, liking, attraction, caring, tenderness, compassion, sentimentality \\
\hline & Lust & Desire, passion, infatuation \\
\hline & Longing & Longing \\
\hline \multirow[t]{7}{*}{ Joy } & Cheerfulness & $\begin{array}{l}\text { Amusement, bliss, gaiety, glee, jolliness, joviality, joy, delight, enjoyment, gladness, happiness, } \\
\text { jubilation, elation, satisfaction, ecstasy, euphoria }\end{array}$ \\
\hline & Zest & Enthusiasm, zeal, excitement, thrill, exhilaration \\
\hline & Contentment & Pleasure \\
\hline & Pride & Triumph \\
\hline & Optimism & Eagerness, hope \\
\hline & Enthrallment & Enthrallment, rapture \\
\hline & Relief & Relief \\
\hline Surprise & Surprise & Amazement, astonishment \\
\hline \multirow[t]{6}{*}{ Anger } & Irritability & Aggravation, agitation, annoyance, grouchy, grumpy, crosspatch \\
\hline & Exasperation & Frustration \\
\hline & Rage & $\begin{array}{l}\text { Anger, outrage, fury, wrath, hostility, ferocity, bitterness, hatred, scorn, spite, vengefulness, } \\
\text { dislike, resentment }\end{array}$ \\
\hline & Disgust & Revulsion, contempt, loathing \\
\hline & Envy & Jealousy \\
\hline & Torment & Torment \\
\hline \multirow[t]{6}{*}{ Suffering } & Suffering & Agony, anguish, hurt \\
\hline & Sadness & Depression, despair, gloom, glumness, unhappiness, grief, sorrow, woe, misery, melancholy \\
\hline & Disappointment & Dismay, displeasure \\
\hline & Shame & Guilt, regret, remorse \\
\hline & Neglect & $\begin{array}{l}\text { Alienation, defeatism, dejection, embarrassment, homesickness, humiliation, insecurity, insult, } \\
\text { isolation, loneliness, rejection }\end{array}$ \\
\hline & Sympathy & Pity, mono no aware, sympathy \\
\hline \multirow[t]{2}{*}{ Fear } & Horror & Alarm, shock, fear, fright, horror, terror, panic, hysteria, mortification \\
\hline & Nervousness & Anxiety, suspense, uneasiness, apprehension (fear), worry, distress, dread \\
\hline
\end{tabular}

Emotions were categorized using Parrot's Emotion Classification (Table 3) that classifies emotions into primary, secondary, and tertiary. ${ }^{22}$ This classification asserts that tertiary emotions are derived from secondary emotions which, in turn, are derived from primary emotions, instead of as a result of a combination of emotions. For this paper, emotions were identified up to the tertiary level but classified and analyzed under the matching primary level emotions: love, joy, surprise, anger, sadness, and fear.

The factors were analyzed as to how they affected the conduct of the consultation, the facilitation of the meeting, and the process of consensus building. A deductive approach was employed to identify patterns, assess the influence of social dynamics in the consultative meetings, and propose explanations. 


\section{RESULTS}

\section{Personality}

Figure 1 shows the observed personality traits in regional consultations. Openness was observed in six of the 17 regional consultations. This personality trait was manifested when stakeholders gave full participation to and were receptive of the consultation activity. Stakeholders freely shared and listened to each other's thoughts and ideas regardless of which institution a stakeholder was representing. Stakeholders kept an open mind when neglected research themes were raised. This openness resulted in stakeholders feeling engaged as their insights were considered in a regional and national health research priority-setting exercise.

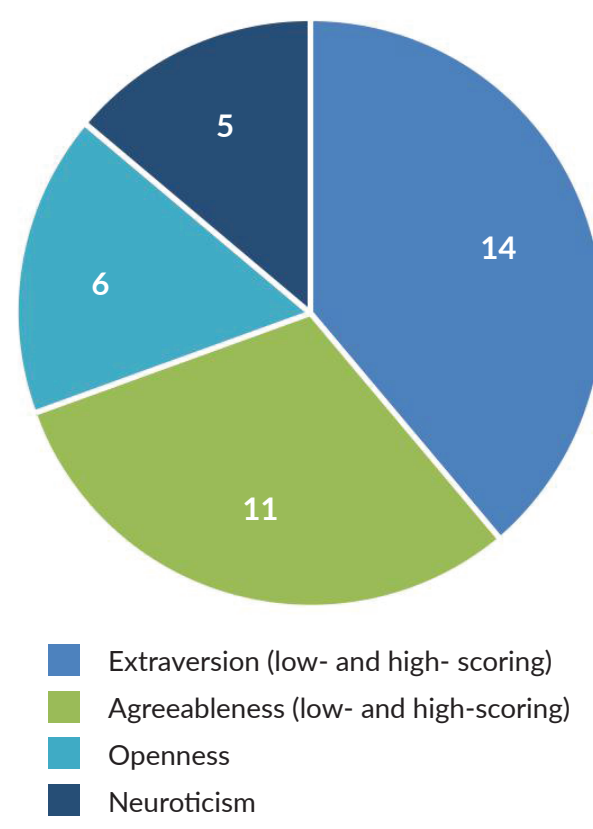

Figure 1. Personality traits observed in regional consultations.

Conscientiousness was observed in two of the 17 regional consultations. In a region in Mindanao, two government agency representatives pointed out neglected and relevant health research topics in the region. Both representatives did not dominate the discussion and seemed to offer their insights based on data and their expertise. In a different region, the government representative committed to validating data presented to the plenary after doubts were cast over their accuracy.

Extraversion was observed in 14 of the 17 regional consultations. High scoring and low scoring behavior for extraversion was observed. High scoring extraversion was seen in the active participation of stakeholders during the two-day consultation. This active participation may be attributed to good expectation-setting regarding their role, discussion of topics that interested stakeholders, their knowledge of processes and functions of the health research environment or being grouped with people of similar interests or fields during focus group discussions. This active participation often resulted in smooth facilitation, discussion, and consensus-building.

Another manifestation of high scoring extraversion was the dominance of one or two stakeholders during the consultation. This dominance sometimes contributed to a livelier discussion, which was observed in a region in Luzon where a representative from an NGO volunteered to lead the plenary in refining the health research priorities. Conversely, the more common observation was that these dominant personalities affected the methodology or results of the research priority-setting exercise. In two regions, dominant personalities often pushed for a research topic through intense and lengthy discussions that sometimes resulted in misunderstandings with the plenary or facilitators. This research topic eventually made its way to the region's research agenda. Extraverted personalities also showed dominance by loudly criticizing inclusion of certain topics which would lead to these being removed from the list of research priorities. Dominant personalities also suggested changes to the methodology of the research priority-setting exercise, such as skipping presentation of national directions or changing the method used to score the research topics. It is important to note that these proposed changes were not always allowed by majority of stakeholders.

Low scoring extraversion was also observed. Some regions were quiet and discussed in a calm manner but showed that they remained attentive by raising questions and ideas when needed. Sluggish discussions were also observed: one region had to be led to a Zumba session as the facilitator noted they were sluggish post-lunch.

High-scoring agreeableness was observed in seven of the 17 regional consultations. Stakeholders showed highscoring agreeableness by expressing appreciation for ideas or being involved in the research priority-setting exercise, having no objections to the data, results, and methods presented, having no appeals to changes in the methodology, or agreeing for their proposed research topics to be removed after a discussion. High agreeableness led to easier facilitation and conduct of the activities.

Low-scoring agreeableness was noted in nine out of 17 regional consultations. Some participants showed lowscoring agreeableness by questioning the relevance of the consultation, doubting the legitimacy and accuracy of regional data presented, changing the methods of the consultation, and difficulty in or not reaching a consensus. As doubts need to be clarified, questions need to be addressed, and consensus needs to be reached, low agreeableness often resulted in the consultation activity going over time.

Neuroticism was observed in five out of 17 regional consultations. Participants felt disheartened and offended when their work pre-consultation was not appreciated, or their proposed research agenda was voted out of the list. Often, 
observed neuroticism was a result of miscommunication or misunderstanding. In a region in Mindanao, one stakeholder debated the inclusion of her health research agenda as she thought the plenary was trying to remove it from the list. However, the plenary was only trying to determine subtopics. Despite efforts by the facilitator to explain and calm the participant, the stakeholder remained combative on the issue. Because the discussion went well over an hour, the other stakeholders expressed annoyance. One stakeholder in a region in Luzon displayed neuroticism by openly expressing dissatisfaction with the final research priority list, resulting in one of the research areas being removed from the list. Stakeholders also became combative when methods were not clearly described or when regional data presented makes the institution they represent look bad. Another notable observation was the anger and dismay expressed by stakeholders in a region due to the absence of an important agency in the consultation.

In another region, a stakeholder excused herself from the activity due to a personal incident concerning a family member. This caused commotion in the room and stakeholders in one side of the room remained unfocused while consoling this stakeholder.

\section{Power dynamics}

Figure 2 shows the power observed in regional consultations. Visible power was observed in all regional consultations. The first observed visible power was the stakeholders present in the regional consultations. There were 312 stakeholders that participated in these consultations, with $89 \%$ representation from government institutions, academic institutions, and NGOs. High representation from these institutions indicate that they are more involved

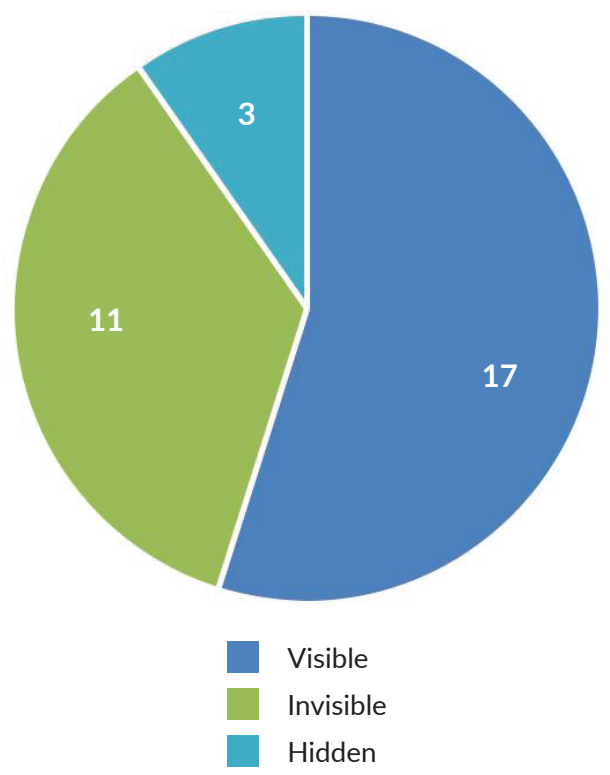

Figure 2. Power observed in regional consultations. in decision-making processes similar to a research priority setting exercise. A higher representation also increases the chance of their suggested research topics being considered as part of the regional health research agenda. This may also indicate that most of the stakeholders were existing consortium members. Their familiarity with the processes and functions of the consortium moved discussions quickly.

Another manifestation of visible power was when an individual spoke or dominated a discussion and how the other stakeholders responded to them or affected the outcomes of the consultation. In one consultation, an individual dominated a discussion and pushed for a research theme; this research theme ended up ranking second in the region's health research agenda. The same individual also pushed for the presentation of the region's development plan before criteria setting. As such, 'Alignment to Regional Development Plan' was included as one of the criteria for prioritization as voted by the stakeholders. Conversely, stakeholders with visible power sometimes did not seek to change outputs or methods but instead served as resource persons for relevant data and neglected topics in the region. People with visible power also served as mediators during discussions. When issues would be raised regarding consortium processes or funding, stakeholders from the Philippine Council for Health Research and Development (PCHRD), Research Agenda Committee (RAC), DOH, or DOST would often answer queries or provide clarification on their processes. Facilitators also used their role to mediate discussions, facilitate decision-making, and bridge differing ideas of stakeholders. It should be noted that, however the visible power was expressed, other stakeholders paid attention and often agreed to their inputs.

Hidden power was observed in three out of the 17 regional consultations. It is difficult to determine deliberate exclusion of certain stakeholders to the regional consultation. The list of stakeholders invited to the consultation was based on the list of existing stakeholders from each regional consortium and results of stakeholder mapping by the organizing team. This process ensured that an effort was made to invite stakeholders from public to private sectors and that access to the consultation is open to all who were invited. In the regional consultations, the consortium showed hidden power through the formal invitation of non-members to be part of the consortium. This membership ensures continued involvement in health research endeavors in the region and enjoyment of this benefit is reliant on being a consortium member. Participants also showed hidden power when an attempt was made at removing a research topic from the research priorities of the region. This attempt was successful in one region in Luzon, wherein a participant persistently criticized the inclusion of a medicinal plant from the initial list of research priorities up until its inclusion in the final list of research topics. The participant's persistent manner resulted in the removal of the medicinal plant from the final list of research priorities, as volunteered by the stakeholder 
who raised this research theme. A similar situation was observed in Region 9, where a participant questioned the need for "LGBT in Health". This participant explained that there are no services that the LGBT community will need that non-LGBT persons will not need. The other participants then explained the need for efforts to get the LGBT community to utilize health services and gender sensitivity in the provision of health services. "LGBT in Health" was then retained as a research theme.

Invisible power was observed in 11 out of 17 regional consultations through the absence of private sector, local government representatives, non-consortium members, and NGOs from some of the consultations. This meant that potential inputs from these institutions were not considered during the consultation. These inputs may have been able to shed light on new or neglected research areas in the region. It is important to note that stakeholders from these institutions were invited to the consultation and so no systematic exclusion was observed. Another manifestation of invisible power was seen in one region in Mindanao. The regional coordinators who contributed to the regional situational analysis were all from one state university. The other stakeholders then expressed that they felt the regional situational analysis was made through the lens of that university. While this was unintentional on the end of the organizing team, invisible power was manifested through the lack of diversity in the team that conducted a regional situational analysis.

\section{Emotions}

Figure 3 shows the emotions observed in regional consultations. Joy was observed in seven out of the 17 regional consultations. This was noted as applause from the

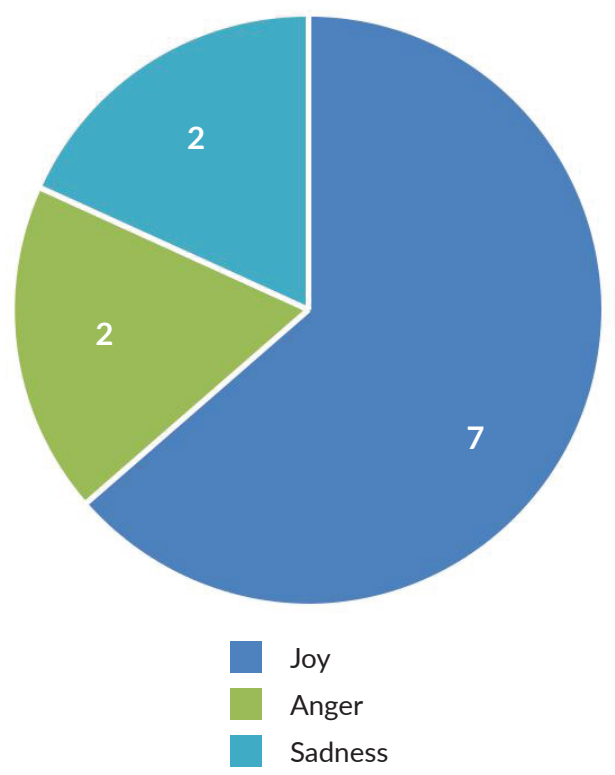

Figure 3. Emotions observed in regional consultations. participants during the presentation of the final list of research priorities or after the two-day consultation. Participants were also laughing, smiling, and seemed delighted when their inputs were taken into consideration or are recognized by the plenary. Contentment and satisfaction was also noted from the participants when no appeals, objections, or changes were made to the final list of research priorities.

Anger was noted in two regions. In one region, a participant expressed frustration and unhappiness over the data presented in the regional situational analysis as it showed weakness of the institution the participant was representing. In another region, participants became annoyed when a participant presented his institution's national agenda, when they were led to believe this was the regional agenda.

Sadness was observed in two regions. This was noted as dissatisfaction from a participant regarding the final list of research priorities. In one region, disappointment was expressed over financial limitations during the conduct of research.

No observations were noted for the following emotions: surprise, love, and fear.

\section{DISCUSSION}

Inclusiveness has been recognized as one of the most important practices in research priority-setting. ${ }^{1}$ In achieving inclusiveness of the process, it is important to ask three questions: 1) Who is the research agenda for? 2) Whose perspectives do we want included?, and 3) Is the process intended to be accessible to all? $?^{2}$ This encourages the output of the research priority-setting exercise to be relevant and a product of consensus or, at least, of rigorous discussion and decision-making. In involving a diverse set of stakeholders, there is a need to recognize that they come from varying socioeconomic, values, experience, expectations, and contextual backgrounds.

In consideration of this, good social conditions must be met during the conduct of consultations to ensure genuine dialogue between stakeholders. ${ }^{23}$ During participatory dialogues involving diverse stakeholders, it is inevitable that social dynamics come into play. This paper investigated the impact of three social dynamic factors (personality, power, and emotion) on the NUHRA 2017-2022 research prioritysetting exercise.

Of the five personalities outlined by the Five Factor Model, high-scoring extraversion was observed the most. Traits associated with extraversion include assertive, talkative, and active. Extraversion is also driven by two components: ambition and sociability. ${ }^{20}$ These qualities of extraversion may manifest as dominance during a teamwork exercise, as shown in our findings. ${ }^{24}$ Previous studies have shown that extraversion is least associated with being able to effectively work with others. ${ }^{25,26}$ This is consistent with our findings, where extraversion of participants sometimes 
caused misunderstandings with other participants or the facilitators. In the same studies, Agreeableness was the personality most associated with effective teamwork. This is also consistent with our findings, where agreeable stakeholders led to easier facilitation and conduct of activities as there were no objections to the data, results, or methods of the consultation.

A study on how extraverts and introverts approach small group discussions found that extraverts mainly differ from introverts in that they provide more contradictions and counterexamples. This inclination often results in a conflictual discussion. ${ }^{27}$ Social dilemma studies on extraversion have shown that extraversion is highly sensitive to reward and punishment. ${ }^{28}$ Evidence shows that extraverts become cooperative in the presence of punishment and even more cooperative than less extraverted individuals once cooperation is compensated with a reward. ${ }^{29}$ During the regional consultation, techniques used by the facilitators for soliciting cooperation from extraverts included 1) listening attentively to suggestions and ideas of dominant personalities, 2) paraphrasing points/inputs as a way of acknowledgment, and 3) thanking them for their active participation.

For inclusive multi-sectoral processes, one of the primary concerns is managing power imbalances between stakeholders. ${ }^{30}$ The most observed type of power in the regional consultations was visible power. By intuition, this power may be identified in terms of numbers. ${ }^{31}$ Majority of stakeholders in the regional consultations were from government agencies, academic institutions, and NGOs. It is then more likely that the developed research agendas were products of inputs from these institutions. Visible power can also be observed as overt influence attempts or subtly framing conversations to favor one choice over another. ${ }^{30}$ This power is drawn from structural sources of power such as budgets, laws, or mandates. ${ }^{21}$ Our results show that stakeholders drew power to use in three different ways: 1) attempt to or successfully influence and change the methods and results of the research priority-setting exercise, 2) raise neglected topics and serve as resource persons, and 3) mediate discussions and address queries related to the institution they represent. Often, stakeholders with visible power also wield hidden power. ${ }^{21}$ This is consistent with our findings where attempts were made by stakeholders with visible power to remove research topics from the research agenda, although not always successfully. Invisible power was manifested as the non-attendance of the private sector, local government, non-consortium members, and NGOs in some regions. This meant their inputs and issues were kept away from discussions during the development of the regional health research agenda. The reasons why these invited stakeholders chose not to participate in the consultation are unclear. Previous studies have shown that low or no participation is a result of long-term exclusion from the process or believing it is not their right to be included in the process., ${ }^{3,31}$
Strategies used by facilitators to minimize asymmetrical power between stakeholders include introduction of each participant, posing icebreaker questions or activities, and mediation of discussions. An analysis of power dynamics in multi-stakeholder processes in third world communities suggest five ways to neutralize the differences between stakeholders. ${ }^{14}$ First, trust and respect must be established between stakeholders in order to move them from differing positions to a mutually beneficial ground reached through consensus. Second, stakeholders may have visible or invisible powers usually associated with resources, participation in decision-making processes, and terms of engagement. Exploration of how these powers are used, actively or passively, may lead to better understanding of the power dynamics in the culture of the stakeholders. Third, tools may be used to clarify the social dynamics between the stakeholders. This may include stakeholder analysis that identifies personal and communal or common and conflicting interests. Fourth, stakeholders can be facilitated to a better decision-making process through relaying ideas and mediating ideas between stakeholders. Finally, recognizing that there are differences in power can be beneficial and may call to attention issues important to groups perceived to be less empowered.

There is increasing consensus that emotions have a definite impact on decision-making and that emotions are needed for rational decision-making. ${ }^{16}$ Emotions can influence attitudes and judgements which, in turn, influence decisions made. ${ }^{32}$ In an inclusive process, stakeholders demand and expect greater engagement. With changing norms on what expression of feeling is appropriate or not in a public setting, trust becomes crucial when dealing with public expressions of emotions. ${ }^{33}$ Participants with stronger emotions, particularly anger, are often louder than satisfied stakeholders and can affect the overall conduct of the consultation. We observed that, when data presented questioned the legitimacy of an institution, anger was expressed by the representative towards the facilitator and damaged the relationship between the two. This affected how the facilitator approached this stakeholder throughout the consultation. Sadness was also observed in the form of dissatisfaction regarding the outputs of the exercise or disappointment in existing processes that limit the conduct of research. Stakeholders with positive experiences, or those who express joy, are easier to facilitate and leads to a more beneficial process. ${ }^{34}$ This is consistent with our findings, where observed joy in stakeholders was due to their inputs being considered and resulted in no appeals, objections, or changes to the methods and results of the research prioritysetting exercise.

Previous research shows that legitimacy of a process is maintained when more stakeholders experience positive emotion. ${ }^{35}$ This indicates that stakeholders have high trust in the facilitator conducting the consultation to the point where it becomes beneficial to the process. Conversely, negative emotions indicate distrust in the process and becomes 
problematic once it begins to hinder the activity, such as forming a discordant relationship between a participant and a facilitator. ${ }^{34}$ Because of the impression that emotion is an unnecessary and irrational factor, attempts are often made to neutralize them in a decision-making process. However, there is an opportunity for facilitators to 1) harness positive emotions to reach a point of benefit for all parties and 2) identify shortcomings that are basis of negative emotions as these are areas that may need to be improved. ${ }^{34}$

\section{CONCLUSION AND RECOMMENDATIONS}

Development of the NUHRA 2017-2022 was guided by the Kingdon Model, which encourages involvement of stakeholders in all streams to allow greater acceptability and adoption of a policy. As our findings and analysis show, ensuring that a diverse set of stakeholders is present is not a guarantee that their inputs and interests are heard on equal footing due to three socials dynamic factors: differing personalities, imbalance of power, and emotions that affect decision-making judgements.

Extraverted personalities are assertive, dominant, talkative, are least associated with good teamwork, and tend to use conflictual language. Therefore, facilitating strategies should be mostly concerned with managing this personality type, particularly when methods employed have many opportunities for open discussions. Strategies to manage extraversion include integrating their inputs to existing outputs, complimenting their efforts, and reaching a compromise. Extraverts may also be encouraged to oblige by reiterating that the methods used should yield a product of consensus.

Imbalances in power is a complex structure determined by access to sources of power (budget, laws, mandates, etc.) and ideologies that form how we perceive power such as beliefs, values, and attitudes. An effective getting-to-know session ensures that participants learn something about their co-participants. Ice-Breakers or Structured Learning Exercises might help participants to be more comfortable with each other. These strategies can establish baseline trust and respect between stakeholders. Facilitators can also deliberately call into attention the participants with perceived least power so that other stakeholders are more obliged to consider their inputs. Beyond the research priority-setting exercise, interventions can also include more persistent and consistent invitation of the private sector, local government units, non-consortium members, and NGOs to begin their integration into the decision-making process and encourage future participation.

The notion that emotions must be neutralized as they are unnecessary in the decision-making process must be changed to harnessing and developing positive emotions and taking note of criticisms from stakeholders that express negative emotions. These criticisms may be areas for improvement in the next research priority-setting exercise.
In hindsight, changes in methodology and outputs might have been reduced if certain aspects of the consultation were considered "non-negotiable". Such aspects include: 1) brainstorming, 2) discussion on the ideas/themes to group related themes together, 3 ) criteria setting and scoring to produce priority themes, and 4) deletion of research themes after priority scoring. A session where participants agree on house rules or terms of engagements during the workshop such as agreeing to disagree, listening to others, and limiting air time may have been more inclusive and avoided conflicts, misunderstandings, and changes in methods and results.

Finally, a consensus-building approach is a method wherein all stakeholders must unanimously agree on all decisions made. When this method is derailed, it cannot be declared that consensus has been reached.This approach relies heavily on seasoned, credible, and experienced facilitators, perhaps on the same level of authority as the most dominant and powerful in a group.

\section{Acknowledgements}

The authors acknowledge the contributions of Professor Marilyn Ellorin-Crisostomo and Dr. Katherine VillegasReyes.

\section{Statement of Authorship}

All authors approved the final version submitted.

\section{Author Disclosure}

All authors declared no conflicts of interest.

\section{Funding Source}

This paper was funded by the Philippine Council for Health Research and Development.

\section{REFERENCES}

1. Viergever RF, Olifson S, Ghaffar A, Terry RF. A checklist for health research priority setting: nine common themes of good practice. Health Res Policy Syst. 2010 Dec 15; 8(36). doi: 10.1186/1478-45058-36.

2. Synnot A, Tong A, Hill S, Craig J. Practical approaches to undertaking research priority setting in health. Australasian Cohrane Symposium. State Library of Victoria, Melbourne; 2015.

3. Barasa EW, Cleary S, English M, Molyneux S. The influence of power and actor relations on priority setting and resource allocation practices at the hospital level in Kenya: a case study. BMC Health Serv Res. 2016 Sep 30; 16(1):536.

4. Nasser M, Ueffing E, Welch V, Tugwell P. An equity lens can ensure an equity-oriented approach to agenda setting and priority setting of Cochrane Reviews. J Clin Epidemiol. 2013 May; 66(5):511-21.

5. Durlauf SN, Young HP. Social Dynamics. Cambridge, MA: The MIT Press; 2004.

6. Brown R. Group processes: Dynamics within and between groups. Cambridge, MA: Basil Blackwell; 1988.

7. American Psychological Association [Internet]. Personality Washington, DC. 2018 [cited 2018 May]. Available from: http:// www.apa.org/topics/personality/.

8. Hoffman L. Applying experimental research on group problem solving to organizations. J Appl Behav Sci. 1979; 15(3):375-91. 
9. Hoffman LR, Maier NR. Quality and acceptance of problem solutions by members of homogeneous and heterogeneous groups. J Abnorm Soc Psychol. 1961 Mar; 62:401-7.

10. Shaw M. Group dynamics: The psychology of small group behavior. New York: McGraw-Hill; 1981.

11. Jackson S, May K, Whitney K. Understanding the dynamics of diversity in decision-making teams. Team Effectiveness and Decision Making in Organizations. San Francisco: Jossey-Bass; 1995.

12. Filley A, House R, Kerr S. Managerial process and organizational behavior. Illinois; 1976.

13. McGrath J. Groups: Interaction and performance. Englewood Cliffs, NJ: Prentice-Hall; 1984.

14. Hiemstra W. Power dynamics in multi-stakeholder processes: a balancing act. Netherlands: ETC Foundation; 2012.

15. Nairne J. Psychology: The Adaptive Mind. Belmont, CA: Wadsworth Publishing; 2005.

16. Lakomski G, Evers C. Passionate rationalism: the role of emotion in decision making. J Educ Adm. 2010; 48(4):438-50.

17. Gallup. Gallup Global Emotions 2016. Washington, DC: Gallup, Inc., 2016.

18. Pippin M, Odasco R, De Jesus R, Tolentino M, Bringula R. Classifications of Emotions Expressed by Filipinos through Tweets. International Multiconference of Engineers and Computer Scientists. Hong Kong; 2015.

19. Kingdon J. Agendas, Alternatives, and Public Policies. Boston: Little Brown; 1984.

20. Mount M, Barrick M, Stewart G. Five-Factor Model of Personality and Performance in Jobs Involving Interpersonal Interactions. Hum Perform. 1998; 11(2-3):145-65.

21. VeneKlasen L, Miller V. A New Weave of Power, People \& Politics: The Action Guide for Advocacy and Citizen Participation. Oklahoma: World Neighbors; 2002.

22. Parrot W. Emotions in Social Psychology. London: Psychology Press; 2000.

23. Abma TA, Broerse JE. Patient participation as dialogue: setting research agendas. Health Expect. 2010 Jun; 13(2):160-73.
24. Sollberger M, Stanley CM, Ketelle R, Beckman V, Growdon M, Jang J, et al. Neuropsychological correlates of dominance, warmth, and extraversion in neurodegenerative disease. Cortex. 2012 Jun; 48(6):674-82.

25. Hough L. The "Big Five" personality variables--construct confusion: Description versus prediction. Hum Perform. 1992; 5(1):139-55.

26. Organ D, Ryan K. A meta-analytic review of attitudinal and dispositional predictors of organizational citizenship behavior. Pers Psychol. 1995 Dec; 48(4):775-802.

27. Nussbaum M. How Introverts versus Extraverts Approach Small-Group Argumentative Discussions. Elem Sch J. 2002 Jan; 102(3):183-97.

28. DeYoung C, Gray J. Personality neuroscience: explaining individual differences in affect, behavior, and cognition. In: Corr P, Matthews $\mathrm{G}$, editors. The Cambridge handbook of personality psychology. New York: Cambridge University Press; 2009.

29. Schroeder KB, Nettle D, McElreath R. Interactions between personality and institutions in cooperative behaviour in humans. Philos Trans R Soc Lond B Biol Sci. 2015 Dec 5; 370(1683): 20150011.

30. Purdy J. A Framework for Assessing Power in Collaborative Governance Processes. Public Adm Rev. 2012; 72(3):409-17.

31. Birkland T. An Introduction to the Policy Process: Theories, Concepts, and Models of Public Policy Making. New York: M.E. Sharpe; 2001.

32. Gutnik LA, Hakimzada AF, Yoskowitz NA, Patel VL. The role of emotion in decision-making: A cognitive neuroeconomic approach towards understanding sexual risk behavior. J Biomed Inform. 2006 Dec; 39(6):720-36.

33. Hochschild A. Emotion Work, Feeling Rules, and Social Structure. Am J Sociol. 1979 Nov; 85(3):551-75.

34. Luoma-aho V. Emotional Stakeholders: A Threat to Organizational Legitimacy? 60th Annual Conference of the International Communication Association. Singapore; 2010.

35. Loewenstein G, Thompson L, Bazerman M. Social utility and decision making in interpersonal contexts. J Pers Soc Psychol. 1989; 57(3):426-41. 